\title{
CORDILHEIRAS DO CAMINHO: HUMANISMO NIETZSCHIANO E GEOGRAFIA FENOMENOLÓGICA
}

Mountain chains of the way: nietzschean humanism and phenomenological geography

Cordilleras del camino: humanismo nietzschiano y geografía fenomenológica

David Emanuel Madeira Davim

Universidade Estadual de Campinas

\begin{abstract}
Resumo
Este escrito, propositalmente edificado como um relato de pesquisa, pretende confidenciar os caminhos percorridos ao longo de um desafio: trazer Nietzsche para um encontro com o humanismo e a Geografia fenomenológica. Foram escolhidas quatro sendas fundamentais que demonstram bem as principais questões, problemas, dificuldades e as possíveis respostas encontradas ao longo de mais de três anos de investigação, reflexão e leitura. Serão destacadas aqui as possibilidades de uma leitura humanista em Nietzsche, a surpresa ao encontrar uma cosmologia em seu esforço filosófico, a reverberação de uma geofilosofia nietzschiana na geograficidade de Eric Dardel e as coincidências e dificuldades na aproximação entre Nietzsche e a ontologia (fenomenologia) hermenêutica de Martin Heidegger.
\end{abstract}

Palavras-Chave: Nietzsche; Geografia; Fenomenologia; Geofilosofia.

\begin{abstract}
This text, purposely written as a research report, intends to confine the paths taken along a challenge: to bring Nietzsche to an encounter with humanism and phenomenological Geography. Four fundamental paths have been chosen which clearly demonstrate the main issues, problems, difficulties and possible answers encountered during more than three years of research, reflection and reading. The possibilities of a humanist reading in Nietzsche, the surprise of finding a cosmology in his philosophy, the reverberation of a Nietzschean geophilosophy in the geography of Eric Dardel, and the coincidences and difficulties in the approximation between Nietzsche and the hermeneutic ontology (phenomenology) of Martin Heidegger.
\end{abstract}

Keyword: Nietzsche; Geography; Phenomenology; Geophysics.

\section{Resumen}

Este texto, intencionalmente escrito como un informe de investigación, pretende limitar los caminos realizados a lo largo de un desafío: traer a Nietzsche para un encuentro con el humanismo y la geografía fenomenológica. Se eligieron cuatro 
caminos fundamentales que demuestran claramente los principales problemas, problemas, dificultades y posibles respuestas encontradas durante más de tres años de investigación, reflexión y lectura. Las posibilidades de una lectura humanista en Nietzsche, la sorpresa de encontrar una cosmología en su filosofía, la reverberación de una geofilosafía nietzscheana en la geografía de Eric Dardel y las coincidencias y dificultades en la aproximación entre Nietzsche y la ontología hermenéutica (fenomenología) de Martin Heidegger.

Palabras-clave: Nietzsche; Geografía; Fenomenología; Geofilosofía.

\section{Carta de acampamento}

[...] O caminho recolhe aquilo que tem seu ser em torno dele; e dá a cada um dos que o percorrem aquilo que é seu. Os mesmos campos, as mesmas encostas da colina escoltam o caminho em cada estação, próximos dele com proximidade sempre nova. Quer a cordilheira dos Alpes acima das florestas se abata no crepúsculo da tarde, quer de onde o caminho ondeia entre os outeiros, a cotovia de manhã se lance ao céu de verão, quer o vento leste sopre a tempestade do lado em que jaz a aldeia natal da mãe, quer o lenhador carregue, ao cair da noite, seu feixe de gravetos para a lareira, quer o carro da colheita o arraste em direção ao celeiro, oscilando pelos sulcos do caminho, quer apanhem as crianças as primeiras primaveras na ourela do prado, quer passeie a neblina ao longo do dia sua sombria massa sobre o vale, sempre e de todos os lados fala, em torno do caminho do campo, o apelo do Mesmo.

Martin Heidegger, O caminho do campo - 1949.

Desfecho, mas ainda sim "em aberto". Sinto que esta condição perdurará em meu modo geográfico de ler a trama do mundo, por um bom tempo. Quem sabe daqui a alguns anos. Quem sabe por toda a vida. Não sei dizer o quanto. E no peso desta dúvida me vem um problema (mais um): se tratar o "em aberto" como condição insolúvel para "ver o mundo" estaria eu determinando um desfecho? Seria o "em aberto" uma cristalização apriorística? Seria a contingência, o inconcluso e o indeterminado um pré-suposto? Espero ao menos retratar tal trama ao final deste escrito. Texto esse que pouco parece um artigo, talvez uma tentativa de diálogo ou relato de pesquisa. Na verdade, deixo aqui por escrito minha confissão, uma revelação sobre minhas perdas e conquistas, a caixa preta de minhas inconsistências, questões, hesitações, hipóteses, equívocos e descobertas. Nada do que um pesquisador poderia ou gostaria de revelar.

O que esperar de todo o inconsistente devir? Sinto não saber. Nem sei se suportaria tal resposta. Mas na atual circunstância do meu movimento investigativo, me 
proponho, ao menos em retórica, responder ao problema que me foi posto, que me afeiçoei e que procurei, durante três anos, decifrar: haveria em Nietzsche um Humanismo?

Como a pergunta acima sinaliza, a princípio, nada do que me propus a responder se tratava de uma busca direta e essencialmente geográfica. Não me atentei previamente com tal obrigação o que, à primeira vista, fez da questão uma tentativa de incursão filosófica. O foco inicial era somente o humanismo em Nietzsche. Pensar uma geografia, a partir disso, cabia não só a minha futura dissertação acadêmica, como também ao leitor, ouvinte ou quem queira pensar comigo sobre o tema. Pois bem! De algum modo a busca por um humanismo nietzschiano avançaria ou se aprofundaria rumo às bases da geografia humanista. Essa era a intuição e esperança.

Ao longo do trajeto caminhei, na maioria do tempo, sob a sombra do um múltiplo e angustiante "não": não deve ser, não pode ser, não dá para ser. Será que não? Todos os "nãos", na maioria advindos de meu apego às tradições da ciência e ao respeito para com a autoridade discursiva do conhecimento formal, me serviram enquanto um estimulante: "sim, vá"! Assim me coloquei no caminho.

"Arado do mau" (com "u"), Gaia ciência, ciência jovial, prespectivismocosmológico-hermenêutico. Cada nomeação e título, no mínimo, espantoso! Só pode ser delírio ou provocação. Quem dera se fosse. Seriam boas desculpas. Mas todas essas ideias me saltaram e invadiram, graças a uma leitura experiencial. Assim penso. Digo isso, pois sinto que vivi cada uma delas, já que me fizeram sentir insegurança, angústia, admiração, euforia, raiva, encantamento, paixão, desejo e esperança.

Todos esses afetos, e outros mais, me visitaram ao longo desse caminho. Caminho que assemelho á uma escalada em trilha de montanha. Uma viagem por cordilheiras que me fizeram oscilar entre o espanto - devido à grandiosidade dos obstáculos - e eufórica audácia de subir, desafiar e ultrapassar rochedos. Florestas ocultas, lagos misteriosos, vales verdejantes, encostas desérticas, campos de matacões e cumes de gelo. Magníficas paisagens filosóficas de surpreender, extasiar, perder e ganhar tempo fruindo, apreciando beleza, espanto e vertigem. Ao compor este escrito, sinto como se retornasse de uma das minhas visitas às terras andinas. Andanças e testemunhos serranos.

Gastei e ganhei tempo com os caminhos difíceis e confusos, beirando precipícios, calculando, inutilmente, como ultrapassar vertentes impossíveis, sendas perigosas e paredões quase intransponíveis. Neste caminho descobrir o quanto sou eficiente em precipitar-me. Tropecei, deslizei e estive ao rés-do-chão muitas vezes, como se tudo recomeçasse do nada. Mas não coube desisti.

Também desperdicei e ganhei fôlego, cansei de andar, adormeci de fadiga, tédio, desconfiança e angústia. Cego, muitas vezes não via mais os caminhos. Desatento, me deixei enganar por trilhas de certezas, desesperado por perceber que o topo ainda 
estava longe e o tempo era curto. As difíceis formas da montanha e os erros de minha pouca visão me iludiram muitas vezes. Apelei pelos guias, interroguei, rudemente outros caminhantes, me aborreci com os silêncios e desencontros.

Cheio de esperança, muitas vezes pensei até que conquistava o cume, mais ao caminhar um pouco mais, novos topos apontavam no horizonte, cada vez mais altos e terríveis. Quantos topos ainda restam para o desafio nessa cordilheira eterna?

Sei e reconheço o olhar, assim como o tom de voz, dos que esperavam pelo sucesso e regresso. Um regresso com respostas em mãos. Anunciarei aqui algumas delas. Repetirei até. Mas não se empolgue caro leitor, eu ainda não voltei da montanha. Se estou aqui é por que montei acampamento no seio desta grande rocha. Parei só para escrever esta carta e anunciar quais montanhas desanuviei. Penso ter desanuviado. Lanço a vocês o antagônico encerramento do que não se fecha, certamente mais um dos últimos e intermináveis diários de uma escalada sem fim.

Nesta andança, destaco quatro sendas fundamentais. A primeira trata-se de reafirmar o primeiro desafio sobre um possível humanismo contido da obra de Nietzsche. Desafio de considero dos mais avançados em minha procura. O segundo, a narrativa de uma hesitação: como me deparei com (até agora) o mais difícil dos meus obstáculos, a aproximação entre Nietzsche, Heidegger e a Fenomenologia. O terceiro trata-se do passo atrás que me levou a discutir a relação entre geografia e o pensamento nietzschiano, tendo Eric Dardel como ponto alto da escalada. No quarto, que na verdade é um retorno ao segundo caminho, resolvi persistir na busca por pistas que desencobrissem um possível encontro entre Nietzsche, Heidegger e a Fenomenologia. O caminho sem fim..., desejo toda fortuna em sua escalada.

\section{A primeira senda de montanha: Nietzsche e o humanismo}

Nietzsche? Um humanista!? Não pode ser. Caso for, deve ser uma absurda brincadeira. Um pensador que afirma o instinto, a guerra, a exploração, o domínio, a ambição, a rapinagem, o egoísmo, a vingança? Seriam esses os adjetivos essenciais do que é humano? Onde se encaixa a busca pela perfeição das nobres virtudes (virtus) que, como lembrado por Heidegger (2009b), fora proposto pelo humanismo romano, assim como pelo helenismo? E a luta por concretizar o homem enquanto sábio, benévolo, fraterno, justo e racional? Devemos abrir mão da boa arte, esquecer a fé, desistir da Filosofia, ou da política, encerrar o compromisso da Ciência, alicerces que consolidaram o nobre projeto civilizatório que nos trouxe até aqui? Como aceitar que aquilo que nos assemelha aos animais se sobressaia ao que nos diferencia enquanto humanos?

Rev. Nufen: Phenom. Interd. | Belém, 9(2), 42-62, mai. - ago., 2017. 
Seria prudente acolher entre os humanistas um filósofo que lançou suspeitas sobre o caráter do que é ser humano? Ainda sabemos as dimensões e limites do que é o humano? Mas o que é o humano? É preciso desvendar os embustes e os antagonismos que a vida nos guarda. Nietzsche (2012b) nos desafia neste sentido. Para ele não somos nada a mais do que o todo ou qualquer parte desse todo. Um ente entre os entes. Nem superiores, tão pouco inferiores. Nossa racionalidade, aquela que elegemos como título e certificado para o nosso assenhoramento sobre o mundo, não passa de um afeto, um sentimento, um impulso e instinto entre os demais. A razão não nos dá direito de superioridade, tão pouco marca ou define o que somos enquanto entes. Para Nietzsche (2011b) razão e consciência são o que há de mais frágil e fátuo no homem, sua potência menor, imatura e despreparada. Ela não é a faculdade mais potente de nossa maior tarefa enquanto humanos. No entanto, ela não é nula, pois nos serve como instrumento, uma virtude a serviço do corpo, nossa razão maior, o verdadeiro ego. Devemos então aperfeiçoá-la, mas, ainda assim, colocá-la sob suspeita.

Para Nietzsche (2011a) o homem é um vivente que só se diferencia dos demais, pois é capaz de valorar o mundo. Portanto, somos uma espécie de animal valorador, que lança luz sobre a escuridão da terra e seus precipícios. O ente que escava profundezas, revelando o caráter e a qualidade de suas entranhas, trazendo-as para a superfície, para que sejam vistas e conhecidas.

Luz!? Não seria a razão esse luz que nos garante o lumiar do mundo? Essa mesma razão objetiva, causal, teleológica e universal que os grandes filósofos sempre defenderam e que Nietzsche (2009) tanto condenava. Não. Para o pensador em questão essa razão é a máquina que nos encoberta a própria terra, desprezando-a e condenando-a, colocando sobre ela um véu de ilusões, enredado por um além-mundo de fantasmagorias e antropomorfismos. Para Nietzsche (2012b), a luz de seu humanismo não resplandece dessa razão de matemático e contador e sim daquilo que nos faz parte do mundo, o que nos coloca em pé de igualdade a todas as outras coisas do universo: o corpo, seu instinto, intuição e sensibilidade.

O corpo e suas faculdades sensíveis é a razão maior do humano. Ele é terra, pois dela faz parte. Para Barrenechea (2009) a visão de corpo em Nietzsche não se trata de simples biologismo ou naturalismo já que estas perspectivas tomam o corpo enquanto estrato material, substancial, atomizado e cindido aos demais corpos e organismos, desprovido de pessoalidade e espiritualidade. Os corpos para Nietzsche (2011a) são contíguos ao cosmo, é parte e totalidade, algo uno e múltiplo ao mesmo tempo.

Ligarmo-nos à terra pelo corpo é o que nos garante conceber e compreender plenamente a existência, a efetividade da vida. Como salienta Barrenechea (2009), o corpo é o fio condutor interpretativo. Ao sentir e questionar sobre seus sintomas, pensamos o 
mundo com o corpo. Para Nietzsche (2011a), o corpo pensa e pensamos imediatamente ao sentir. Ao traduzir essa pensar e sentir corpóreo em pesos, valores e qualidades, interpretamos a vida com arte. Assim nos consumamos como seres humanos. $O$ animal que valora. Aquele que anuncia com poética o que sente e o que pensa mediante as sensações corpóreas. Eis as bases do humanismo nietzschiano que tanto procurava. A valorização do corpo, da imanência e intuição é seu projeto de conhecimento (Ciência-Arte-Filosofia), meu primeiro escalar montanhês, a tarefa que, segundo Nietzsche (2011b), o homem e a Filosofia deveria se dedicar com maior interesse, vontade e paixão para doar a terra um sentido, um sentido verdadeiramente humano, que eclode da própria vida e não de um mundo-além.

\section{Segunda senda de montanha: Nietzsche e a fenomenologia (?)}

A pior e melhor das montanhas. A mais dura e glacial, mas, ao mesmo tempo, um desafio instigante, talvez o maior dos que eu me deparei até então. Seu topo parece composto por muitas pontas, sendo uma já posta em meu trajeto desde o principio: Heidegger, leitor e apreciador da filosofia nietzschiana. Sorte minha ou azar? No que isso me auxiliaria ou me despistaria durante o caminho?

Paralelo à busca por um humanismo nietzschiano, me pus a pensar em uma possível proto-fenomenologia nietzschiana via Heidegger que, no princípio, era a mais forte dentre as pistas que eu tinha. Primeira dificuldade: em seus principais escritos sobre Nietzsche, Heidegger (2010) me presenteou com uma cordilheira aparentemente intransponível, a saber, Nietzsche deve ser compreendido como o último e mais extremo dentre os metafísicos.

Ao ler a obra nietzschiana, uma das impressões mais aparentes e nítidas revelase nos ataques violentos à metafísica tradicional. Para Nietzsche (2009), a Filosofia triunfante se afastou da vida, do mundo concreto e de sua imanência em virtude de uma maior valorização a um mundo ideal e transcendente. A metafísica, portanto, era posta por Nietzsche enquanto causa maior para o efetivo desprezo humano sobre a vida, o corpo, a vontade e a terra. Desprezo esse gestado no medo e ressentimento diante dos estímulos da

existência, tendo destaque a dor, o sofrimento, a incerteza e a angústia. Mas tratar Nietzsche enquanto um anti-metafísico era, na visão de Heidegger (2010), uma má interpretação de seus leitores, na verdade um pré-juízo sobre o poeta de Assim falou Zaratustra. Para a minha busca, qual seria a gravidade de tal leitura?

Para Heidegger (2009b), toda a trajetória da Filosofia foi marcada por uma questão diretriz e estruturante sobre o pensamento, sendo esta: o que é o ente? Em sua nova postura filosófica, Heidegger propõe a questão fundamental sobre o que até então fora 
posto de lado e até mesmo esquecido pela tradição, a saber: o que é o Ser? A fenomenologia enquanto caminho para pensar o problema proposto por Heidegger se debruça atentamente sobre esta conduta ontológica. No entanto, para que a fenomenologia, enquanto ontologia, se ponha em tarefa, ela deve se desvencilhar de todo e qualquer princípio de incondicionalidade do pensamento, isto é, deve suspender a metafísica. Suspender a metafísica, por sua vez, é uma conduta filosófica libertaria e que nos permite dar os primeiros passos para a máxima da fenomenologia: voltar à coisa nela mesma. 0 próximo passo é se permitir sentir e estar no mundo, em sua facticidade, se valer da imanência sensível e dos afetos para então pensar o que deve ser pensado, de maneira profunda e cuidadosa.

Em minha interpretação a Heidegger (2010), esse caminho fenomenológico não é pleno em Nietzsche, isso por que, na visão do filósofo, Nietzsche estabeleceu, em sua inversão ao mundo cindido de Platão, a vontade de potência e seu devir (o eterno retorno do mesmo) enquanto incondicionalidade, princípio metafísico, caráter fundamental do ente e nova diretriz para o pensamento. Vontade de potência como um a priori causal e estruturante sobre o ente. Eis o abismo de meu caminho. Eis o cume impossível do meu horizonte.

Impossibilidade! O mais duro dos "nãos". Talvez esta seja a palavra ideal para anunciar o tamanho da minha frustração diante de tal julgamento. Mesmo animado com as possíveis e prévias intuições sobre as coincidências entre Nietzsche e a fenomenologia, a leitura a Heidegger (talvez o fenomenólogo que mais explorou o pensamento nietzschiano), colocou diante de mim a montanha entre as montanhas.

E agora? Como enfrentar e superar Heidegger? Poderia sonhar com tal prepotência? Meu segundo "não". Bem no início de minha jornada eu já tinha comigo essa perturbação torturante. A princípio, a ideia foi desistir do caminho, não afirmar a fenomenologia nietzschiana, mas tentar escavar e identificar algo que evidenciasse tal encontro, ideias que unissem Nietzsche e a fenomenologia de Heidegger. Por recomendação, pensei em buscar em outros, fenomenólogos ou pensadores que se inspiraram na fenomenologia, novas pistas para supostas intersecções. Ao ler o Homem e a Terra do geógrafo Éric Dardel vislumbrei uma pista, que, aliás, está nítida para quem queira confirmar. Dardel (2011) havia lido o filósofo Gaston Bachelard (2001), que por sua vez leu e escreveu sobre Nietzsche. Para animar ainda mais meu caminho por estas cordilheiras, Dardel (2011) cita Nietzsche em algumas passagens de sua obra capital.

Ao maravilhamento de Hölderlin se opõe a vontade de Nietzsche, áspera e dura como um desafio: Uma vereda que subo com insolência, uma vereda má e 
solitária, uma vereda de montanha criada sob o desafio dos meus passos (Dardel, 2011, p.17).

Nietzsche, como mostrou Bachelard, fugia do calor úmido da planície, onde a melancolia espreita as almas fracas, e projetava sua imaginação para um mundo frio, claro, transparente, duro como sua dureza moral, próxima da crueldade (Dardel, 2011, p.24-25).

Além disso, o geógrafo fez uso de termos semelhantes aos utilizados pelo filósofo, a saber: vontade de potência e vontade de poder, sobretudo em seu sentido conceitual reativo, ou seja, como vontade de verdade, desejo por representar o mundo como medida nos discursos da técnica, assim como das ciências objetivas, algo que trataremos mais adiante.

Alegria e esperança. Naquele momento adiei subir a montanha chamada Heidegger. Pretendia explorá-la depois, com mais entusiasmo, melhores ferramentas, instrumentos e novas pistas. Em meu horizonte já apontava outro monte, uma montanha chamada Geografia.

\section{Terceira senda de montanha: a geografia nietzschiana}

Uma senda cobrada desde o princípio de minhas anunciações. Nada mais natural, porém escasso para o meu contexto. Quando de fato dei conta da geografia em meu trabalho, concluí que ela sempre esteve por perto, disfarçada, oculta, porém bem diante dos meus olhos. Bastava "ver melhor" para identificá-la. Até intuí sua presença em muitos momentos, mas não sabia anunciá-la. Em meio às investigações sobre um possível humanismo nietzschiano, me deparei, ao ler os textos de Scarlett Marton (2010), com a ideia fascinante de uma cosmologia. Um mundo, assim como cada uma de suas coisas, pensado como um corpo continuum e finito, um emaranhado de impulsos que, como serpentes enciumadas entre si, lutam uma contra as outras por afirmação, efetivação e superação constante. Assim são os homens, assim repercutem as ideias e assim se mantém o cosmo, um jogo eterno e caótico, destrutivo e ao mesmo tempo edificante, sem caráter divino, lei, valor, princípio ou finalidade, constituído por múltiplos impulsos, forças, vontades de potências que desejam cada vez mais desdobrar-se em mais potência. Assim Nietzsche pensou o mundo, o verdadeiramente ente em sua totalidade. Uma leitura de cosmo ao sabor da era homérica dos gregos arcaicos.

Desta visão de mundo, percebida em meio à experiência de leitura, principalmente às obras Humano, Demasiando Humano, A Gaia Ciência, Assim falou 
Zaratustra e Para Além do Bem e do Mal, me adveio, enquanto interpretação, a multiplicidade de sentidos sobre a terra de Nietzsche (2011a, 2011b, 2012, 2014), potencialmente o sentido cerne de sua geofilosofia. Em primeira instância, a terra em Nietzsche corresponderia à subtaneidade desse continuum cósmico apresentado, isto é, uma alçada sensível, corpórea e circunstancial, uma dimensão do mundo que nos é acessível pela imanência e sensibilidade. Uma subtaneidade percebida que também corresponde à contiguidade (ser-com; ser-junto-a) entre entes constituintes deste instante e situação vivida.

Por ser relativa ao sentido nietzschiano de cosmo, a terra traz consigo adjetivos semelhantes: finita, eterna, mutante, caótica, dotada de impetus próprio, hábitos breves, cíclicos e desprovida de valor. Para Nietzsche (2011a, 2011b) terra, corpo, vida, homem e natureza são e compõe o mesmo ente, a dimensão que a Filosofia tradicional e sua metafísica escolheram evitar e condenar por mais de dois milênios. Retornar em fidelidade a esse sentido de terra, se dispor e corresponder aos seus estímulos é o que propõe Nietzsche (2011b) em suas lições. Retornar à terra e aos impulsos de sua vontade é retornar às reais possibilidades humanas de conhecer e compreender o mundo e, a partir deste esclarecimento, ir-além, ser-outro (alhures) e ser-mais. Encontrar no sentido de terra elementos de uma geografia nietzschiana acabou por complementar a noção e interpretação sobre o humanismo em Nietzsche, ou seja, retornar à terra e se valer da imanência corpórea para então conceber e conhecer a existência junto a efetividade das coisas.

Por que não pensar uma geografia a partir desta destes sentidos cosmológicos de terra e mundo? Ao meu ver, o geógrafo Eric Dardel (2011) já havia feito semelhante apropriação em sua geograficidade. Talvez uma apropriação indireta, em virtude de leitura à outros filósofos. Mas, devido à erudição de Dardel, duvido muito que tenha sido um reflexo inconsciente.

Para Dardel (2011), em sua visão sobre a realidade geográfica, homem e terra compõem uma efetividade imanente, com impulsões próprias, viva e autônoma em sua dinâmica. Tal realidade se manifesta como um verdadeiro jogo conflituoso de forças, que varia entre estímulos, respostas e resistências entre seus constituintes contíguos. Essa vitalidade do mundo efetivo sensibiliza o homem por meio de uma espécie de apelo e confidência (ou mesmo linguagem), que por meio de suas ressonâncias e repercussões convoca o homem para sua tarefa fundamental: interpretar, lançar luz sobre a terra, valorar e agir sobre ela conforme tal leitura. Uma geografia primeira, ontológica e hermenêutica, também marcada por um movimento conflituoso entre ocultamento e decifração, sombra e luz, terra e homem.

Neste movimento, ligeiramente apresentado, Dardel (2011) revela incorporações filosóficas á alguns pensadores contemporâneos, a exemplo de Heidegger, Bachelard e 
Nietzsche. A leitura de uma realidade autônoma e pulsante, marcada por contiguidade e conflito entre seus entes, ao meu ver, faz nítida referência aos aspectos da cosmologia marcante no pensamento de Nietzsche. Já a luta entre ocultamento (sombra) e revelação (luz), correspondente à relação homem-terra, assim como ao ato interpretativo, demonstra coincidências não só com o princípio de interioridade ou contiguidade do embate terramundo em Heidegger (2009b), mas também à tragédia nietzschiana envolvendo a luta entre Apolo e Dionísio.

Como salienta Machado (2006), o trágico agonismo envolvendo Dionísio e Apolo, expressa, no pensar nietzschiano, o combate entre terra e homem, sombra e iluminação. Dionísio seria o Deus estrangeiro que invade Tebas, trazendo as virtudes telúricas de volta à humanidade: a libertação da vontade, do corpo, dos instintos, o poder da natureza, o desejo, o amor próprio, a ânsia por domínio, a destruição que promove renascimento, mudança e diferença. Apolo é o seu inverso, a consciência, a razão, a ordem, o pensamento, o poder interpretativo e edificante do homem e de sua arte. Neste agon (justa ou combate) trágico, as duas porções se complementam em um jogo antagônico. Dionísio provoca e alimenta Apolo com estímulos e vontades à decifrar. Apolo, em resposta, busca domar e apaziguar as potências dionisíacas com sua racionalidade. Dionísio, por sua vez, reage ao apaziguamento apolíneo com desobediência e caos, proporcionando assim a eterna transformação de tudo e a incondicionalidade do mundo. A tragédia nietzschiana trata-se de uma guerra interminável entre homem, terra e seus impulsos que constroem e reconstroem o cosmo.

O como salientado por Davim (2015), a luta entre homem e terra, assim como entre as potências do cosmo, também corresponde ao embate presente no ato de concepção e compreensão da realidade geográfica. A dinâmica envolvendo ressonância e repercussão entre apelo e resposta, revela-se em Dardel (2011) uma similaridade à Fenomenologia da Imaginação de Bachelard (1978). O manifestar da terra como linguagem, uma voz e convocatória que se expressa como imagem e paisagem, nos leva a pensar em uma influência bachelardiana presente em O Homem e a Terra. Imagem e linguagem que propagam e repercutem como uma espécie de força, uma energia que tanto Bachelard (2003a, 2003b) quanto Dardel nomeiam de vontade, um querer e afeto, presente não só na subjetividade humana, mas em todas as coisas concretas.

De onde advém tal entendimento sobre a vontade? Provavelmente de influências cosmológicas nietzschianas? Tal suspeita seria reforçada ao me deparar com o uso do termo vontade de potência, assim como seu sinônimo (vontade de poder), citadas no texto de Dardel (2011) para se referir não só ao sentido afirmativo, como também e sobretudo em seu sentido niilista.

Rev. Nufen: Phenom. Interd. | Belém, 9(2), 42-62, mai. - ago., 2017. 
Depois da Idade Média e de sua inquietude metafísica, ao final do humanismo atento aos problemas psicológicos, morais e políticos do Homem, o mundo ocidental volta-se para a Terra, o Espaço e a Matéria. Sua vontade de poder, impaciente em se instalar nas dimensões do mundo exterior, se apodera do universo pela meditação, o cálculo e a análise (Dardel, 2011, p.01).

No momento em que se propaga por todo o lado essa raça de homens que reduzem o espaço a um objeto, a terra em uma matéria-prima ou em fonte de energia industrial, que dispõe de tudo e mesmo da vida humana soberanamente, é necessário admitir que essa energia secreta que erige o homem de hoje sobre sua própria liberdade não difere essencialmente de uma vontade de potência, segura de toda força de seu poder-ser e muito permeável à paixão (Dardel, 2011, p. 92).

O vocabulário da terra se propaga como um impulso (força) que incita no humano, múltiplas vontades, dentre elas, a vontade de correr, descobrir e explorar a terra, o elemento dionisíaco, fundamental para uma geografia em ato e primitiva. O oposto desse impulso também incita no homem a dimensão apolínea da vontade, isto é, a vontade de medir, calcular e analisar as coisas, princípio correspondente às ciências positivas, a qual Nietzsche (2011a) denominou de vontade de verdade.

Por estas coincidências entre Nietzsche, Heidegger, Bachelard, presentes na obra capital de Dardel, é possível pensar esse importante fundador da geografia humanista e fenomenológica enquanto um pioneiro em se valer da cosmologia, assim como da geofilosofia nietzschiana enquanto um dos fundamentos para sua geograficidade.

Essa apropriação nietzschiana na Geografia não se encerrou com Dardel. Tão pouco esse campo do conhecimento foi o único a perceber em Nietzsche uma reflexão geográfica ou mesmo espacial. Já na primeira metade do século $X X$, filósofos como Ernest Bertram, Theodor Lessing e Karl Jasper sinalizaram a possível existência de filosofemas de caráter paisagísticos e geofilosóficos nos escritos de Nietzsche. Os filósofos Stephan Günzel (2003) e Charles Feitosa (2011) aprofundaram tal sinalização ao encontrar indícios de uma geofilosofia de origem nietzschiana em pensadores que leram e se apropriaram do empreendimento nietzschiano. Dentre esses destacamos: Heidegger - em sua reflexão sobre o prespectivismo contido nos sentidos de sol e lua, luz e sombra, assim como no sentido de pico e abismo enquanto o embate terra-mundo e o devir enquanto eterno retorno; Bachelard - no voo ascensional enquanto alhures e superação, rumo ao além-do-homem; Lyotard - em sua interpretação do navegar sobre os oceanos enquanto risco de perecimento, esperança e glória, ao encontrar ilhas e terra incógnita; Deleuze e mais uma 
vez Heidegger - ao interpretar o deserto nietzschiano, não só como austeridade e sofrimento, mas o estar desacompanhado de seus pares (pensadores ocidentais-europeus) para então pensar profundamente aquilo que deve ser pensado, em total solidão (Günzel, 2003).

Para Feitosa (2011), Nietzsche seria o primeiro a empreender o desafio de geograficizar a Filosofia, tentativa que influenciaria outros filósofos. Na visão de Günzel (2003), a reflexão geofilosófica de Nietzsche trata-se na verdade de um posicionamento crítico diante da tradição filosófica. Suas metáforas proporcionam um enfrentamento ao triunfo da transcendência, assim como um apelo para que a Filosofia volte seu interesse à imanência, à corporeidade, à terra e toda a facticidade do mundo das coisas. Em minha visão, talvez este retorno a imanência e sua importância ao pensar seja a primeira abertura a coincidir o pensamento nietzschiano com a fenomenologia.

Na visão dos filósofos Dorian Astor (2013), Fréderic Gros (2010) e Paulo D'iorio (2014), Nietzsche se diferenciou dos demais pensadores por fazer de suas experiências no mundo subsídios para seu pensamento inovador. Atento aos sintomas do corpo (dor e prazer), além de viajante entusiasmando e incansável andarilho, Nietzsche fez de sua tarefa uma filosofia ao ar livre, experienciada e escrita com os pés, em meio as mais diferentes paisagens. Frias montanhas alpinas, vales e densas florestas, ensolarados litorais mediterrâneos e charmosas cidades interioranas presentearam Nietzsche com afetos e sensações únicas, que em seu pensamento hermenêutico se desdobraram em pesados enigmas, ideias desafiadoras e surpreendentes. Por inspiração na leitura do Wainwirght (2010) e considerando Nietzsche enquanto um filósofo que sentiu, pensou e escreveu sobre o mundo (e estando junto ao mundo), como não destacar sua importância para um pensar geográfico? Como não suspeitar também de uma possível filosofia ou fenomenologia geográfica em Nietzsche?

Atento a estas possibilidades, o sociólogo e filósofo Henry Lefebvre (2006) nos trouxe mais elementos para pensar Nietzsche enquanto um filósofo que refletiu sobre o espaço. Para o sociólogo, Nietzsche foi um dos primeiros a olhar para o abismo que separa o mundo mental do real, propondo uma visão holística sobre estas dimensões, oferecendo assim elementos para superar as deficiências da alienação e acriticidade das ciências (dentre elas a Geografia). Sua crítica ao idealismo platônico, assim como ao primado do tempo sobre o espaço, contido na dialética de Hegel, fez de Nietzsche, segundo Lefebvre, um pensador que valoriza não só o instante (o agora), mas o espaço (o aqui) enquanto dimensão concreta e fundamental para compreender o jogo de contradições que constituem a realidade.

Já a geógrafa Anne Buttimer teceu uma interpretação animadora para a questão problematizada em minha primeira senda investigativa, a saber: haveria em Nietzsche um 
humanismo? Para Buttmer (1990) isso seria muito possível, pois, em sua avaliação, o filósofo de Assim falou Zaratustra, trouxe, na poética de seus aforismos, o grito estremecedor da Fênix humanista, isto é, o alerta para as virtudes humanas, esquecidas ao longo do desdobramento e amadurecimento do humanismo convencional, suas instituições e estruturas faustianas do conhecimento. Para Buttmer, Nietzsche, assim como Heidegger, Göethe, Hölderlin e Kierkegaard, denunciou a decadência do logocentrismo iluminista, chamando atenção para a importância da estética, das emoções, paixões e vontades, além de sinalizar a importância de temas envolvendo a moral, a psiquê e as artes.

Segundo o trabalho de Davim (2016), a iniciativa de Buttmer reverberaria na década seguinte, momento em que estudiosos e geógrafos de orientação humanista e cultural (dentre eles: Joel Wainwright, Andrew C. Comrie, Paul Kingsbury, Carl T. Dahlman, Clayton Rosati, Pamela A. Mullins-Baker, Caroline Joan (Kay) Picart e Jane Jacobs) participaram da reunião da Association of American Geographers (AAG), em 2006 na cidade de Chicago-EUA, trazendo elementos da geofilosofia de Nietzsche enquanto temática central. O encontro resultou anos depois na publicação de uma coletânea de artigos sob o título: "Friedrich Nietzsche and Geography", edição especial do periódico canadense An International E-Journal for Critical Geographies (ACME). Apesar da representatividade proporcionada pela publicação do periódico ACME, Kingsbury (2010), assim como Peet e Hartwick (2009), Gomes (2011), Haesbaert e Bruce (2002) admitem que a plena incorporação da filosofia nietzschiana na Ciência, assim como na Geografia vem, aos poucos, ocorrendo em suas tendências pós-estruturalistas e pós-modernas.

Ao decorrer desta longa senda geográfica pude trazer, ao menos, a proposição de que, no pensamento nietzschiano, cabe sim explorar uma reflexão humanista e geográfica. Portanto, Nietzsche pode ser considerado fundamento importante para a Geografia Humanista, enquanto o círculo mais abrangente de nossa orientação filosófica e epistêmica. Penso que a este extraordinário filósofo cabe, agora, as devidas saudações e interesses de estudo. Porém, o maior dos pesos retorna a me desafiar: seria Nietzsche também um fenomenólogo? Ou, ao menos, um pensador a oferecer possibilidades à fenomenologia? O semblante da montanha mais desafiadora apontou novamente.

\section{Quarta senda de montanha: revisitando Heidegger e sua fenomenologia}

Trilhar a quarta senda, tratou-se na verdade de retrilhar a segunda, dar continuidade a um caminho em que hesitei, porém não desisti. Tal movimento não se trata de uma repetição. Talvez o retrilhar seja, na verdade, um novo trilhar, portanto o "segundo" que se fez "quarto". Por outro lado, o problema ainda parece ser o mesmo: seria Nietzsche 
um fenomenólogo? Teria seu pensamento reverberado em algum filósofo da fenomenologia, a exemplo de Heidegger?

Em uma passagem do prefácio de sua Fenomenologia da Percepção MerleauPonty (1999) me presenteou com a seguinte pista:

[...] a fenomenologia se deixa praticar e reconhecer como maneira ou como estilo; ela existe como movimento antes de ter chegado a uma inteira consciência filosófica. Ela está a caminho desde muito tempo; seus discípulos a reencontram em todas as partes, em Hegel e em Kierkegaard, seguramente, mas também em Marx, em Nietzsche, em Freud. [...] (Merleau-Ponty, 1999, p. 2).

Deste modo, considerando as distancias, poderíamos ao menos pensar que a fenomenologia esteve a caminho via o pensamento de filósofos como Nietzsche. Mas quais as trilhas desse caminho? Quais particularidades deste caminho se devem, ou se abriram pelo próprio caminho do pensamento nietzschiano? Seria Heidegger uma trilha das mais evidentes?

Em seus escritos sobre Nietzsche, Heidegger (2010) parece se preocupar em deixar bem claro uma diferenciação entre sua proposta e ao do filósofo de $A$ Gaia Ciência, assim como um movimento de ultrapassagem. Como já tratado, Para Heidegger, Nietzsche, o último e mais extremo dos metafísicos, consumou a questão diretriz da Filosofia (o que é o ente?), mas não respondeu, ou se quer propôs responder sua questão fundamental (o que é o Ser?). Questão e tarefa na qual Heidegger (2009b) se considerou, até o momento, enquanto o único pensador sensibilizado e comprometido. À primeira vista, tal enfrentamento distância radicalmente os filósofos. Como superar tal distanciamento? Ou melhor, como encontrar neste distanciamento uma comunhão?

Não poderia resolver esse problema sozinho. Por isso, recorri ao que há de mais respeitável e consistente nos recentes estudos nietzschianos. Os filósofos Werner Stegmaier (2013) e Müller-Lauter (2009) nos dão duas valiosas pistas para pensar o enfrentamento Nietzsche-Heidegger. A primeira delas trata-se do princípio de incondicionalidade do pensamento nietzschiano, ao qual Heidegger, na visão destes especialistas, provavelmente desconsiderou. Na leitura de Stegmaier e Müller-Lauter o sentido da vontade de potência e seu devir, enquanto eterno retorno do mesmo, não se trata de um núcleo ou princípio causal e incondicionado do ente em sua totalidade, como um dia interpretou Heidegger (2010). Muito pelo contrário. Para estes comentadores, a vontade de potência, em seu caráter antagônico e indeterminado, é sempre consequência de si mesma, ou seja, ela é o resultado e ao mesmo tempo fundamento de sua própria multiplicidade 
cósmica, caótica e conflituosa de impulsos, que, por sua vez, estão entrelaçados entre si, condicionando-se eternamente.

Retomando ao cerne da cosmologia nietzschiana, vale a pena retomar que o mundo, para Nietzsche (2011a, 2011b), não tem ordem, origem ou fim, tão pouco a vontade de potência se assemelha aos princípios tradicionais, universais e rígidos da metafísica, a exemplo da razão, espaço, tempo, substância, átomo, essência, Deus, Ser ou coisa-em-si, entre tantos outros. A atenção que Nietzsche dá ao mundo das coisas concretas como único plano efetivo de existência também não se trata de uma inversão platônica como posto por Heidegger (2010). Para Barrenechea (2009) Nietzsche não entende o mundo efetivo dos corpos como um mundo aparente, até por que não há em contraposição um mundo de essências que deprecia a vida. Para Nietzsche (2011b) só há um único mundo, a dimensão do corpo, da terra e da vida que em si é uma condição não-aparente, tão pouco acolhedor de alguma essência transcendental.

A nosso ver, rebater a vontade de potência e seu devir enquanto princípio metafísico incondicionado, conduz a filosofia de Nietzsche para uma maior proximidade com Heidegger, assim como a uma abertura ou possibilidade de leitura fenomenológica de sua obra.

A segunda pista para o enfrentamento Nietzsche-Heidegger se refere ao que Stegmaier (2013) compreendeu sobre as considerações de Nietzsche a respeito da verdade. Para o filósofo, o próprio Heidegger reconheceu em Nietzsche uma apropriação aristotélica para compreender o sentido de verdade. Para Aristóteles, segundo Stegmaier (2013) assim como para Nietzsche, a verdade não está dada de imediato ao homem, pois ela é alcançada por meio de um ato (ação) que corresponde a dois movimentos principais. Primeiro, a postura de colocar-se em contiguidade (em relação), diante da situação, ente ou coisa a ser concebida e investigada, ou trazer para si algo que já está dado e será concebido, ou decifrado, em sua verdade. Segundo, a criação interpretativa (arte enquanto fazer - poiesis) diante da coisa, ente ou situação concebida e investigada. No entanto, a diferença entre Nietzsche e Aristóteles está na incondicionalidade aristotélica da razão, presente tanto no sujeito (como consciência), quanto no objeto (como substância).

Para Nietzsche (2014), não existe uma ordem hierárquica entre sujeito e objeto, pois tudo faz parte de um grande entrelaçamento de corpos, entes, afetos e pensamentos, profundamente enamorados no instante vivido e experienciado, lutando entre si por efetivação, condicionando-se mutuamente, destruindo-se e reconstruindo-se em uma busca infindável por superação e diferenciação. É diante deste instante e situação de vida, assim como em uma atitude interpretativa à esta, que o homem se põe na tarefa filosófica de buscar a verdade. Uma verdade que o próprio Heidegger (2010) em sua leitura a Nietzsche reconheceu como de natureza circunstancial, plural, singular e particular, avessa ao sentido 
pensado pela metafísica tradicional. Na visão de Heidegger (2010), a verdade em Nietzsche corresponde ao verdadeiramente ente, que, por sua vez, se manifesta na aparência, ou na faticidade. Nesse sentido sua busca trata-se mais de um ato artístico do que filosófico ou científico, pois não visa encontrar uma categoria, essência una, indubitável, absoluta e universal. Para Nietzsche, segundo Heidegger, a verdade metafísica da tradição e do pensamento moderno não passa de fantasmagoria e sonambulismo delirante, uma grande farsa voltada para um além-mundo, sendo a arte o seu contrário, o que há de mais próximo da terra e da verdadeira verdade, ou seja, a menor e mais verdadeira dentre as farsa e mentiras.

Em nossa interpretação, essa perspectiva nietzschiana de verdade corresponde a um dos elementos centrais do pensamento heideggeriano. Em associação ao sentido de verdade também os sentidos geofilosóficos e cosmológicos de terra e trágico em Nietzsche, podem ser claramente sinalizados enquanto fundamento da fenomenologia existencial de Heidegger. Em virtude desta interpretação é que declaramos possível a abertura, assim como os encontros e aprofundamentos entre Nietzsche e a Fenomenologia, sobretudo a de orientação heideggeriana. Cabe então um breve esclarecimento sobre esta possível comunhão.

Para os estudiosos Jeff Malpas (2008) e Ligia Pádua (2012) Heidegger, ao decorrer de sua trajetória, passou por uma viragem de caráter geográfico ou topológico. Uma topologia que, segundo Dal Gallo e Marandola Jr. (2014) se faz presente na geograficidade de Eric Dardel. Na visão dos autores, essa topologia se deu especificamente em virtude de dois termos fundamentais da filosofia heideggeriana: ser-no-mundo (in-derWelt-sein) enquanto experiência imanente e ser-aí (Das-sein) enquanto lugar circunstancial da existência, da questionabilidade e da revelação do Ser. Assim como Nietzsche, Heidegger, segundo Malpas (2008) e Pádua (2012), também se apropriou da contiguidade (ou interioridade) aristotélica de colocar-se em situação, (ser-junto-a e ser-com o mundo) para o ato de desvelamento da verdade no Ser. A situação no caso trata-se no lugar (o aído-ser) enquanto ponta de lança (ortschaft), isto é, o topos, o chão, o epicentro, a terra (ou solo) onde os entes, em sua totalidade (coisas e pensamentos), se reúnem, concentram-se e se entrelaçam intimamente, reverberando em uma espécie de abertura, (ou clareira), um acontecimento que sinaliza, ilumina e possibilita o desencobrimento do que estava obscuro, oculto nas sombras do não conceber e não saber.

Esse sentido de lugar em Heidegger sinaliza muitas similaridades com nossa interpretação sobre o sentido de terra em Nietzsche, ou seja, a multiplicidade súbita do cosmo percebida pela corporeidade, por uma alçada sensível, um instante conflituoso de vida onde as vontades de potência se reúnem e manifestam seus afetos. A terra em Nietzsche (2011a) é a dimensão imanente, assim como o fundamento da existência para 
onde o humano, antes ludibriado pela metafísica, deve agora retornar em fidelidade. Em proximidade ao lugar enquanto terra é que o humano pode de fato alcançar a sua superação (além-do-homem) e fazer valer o grande estilo, a junção entre arte, filosofia e ciência que tanto Nietzsche recomendou.

Para Heidegger (2009a) ao se imiscuir nesta situação de abertura (ou lugar), o humano, enquanto o único ente que existe e questiona o Ser, é interpelado e afetado, sensivelmente, pela circunstância. No questionar e pensar cuidadosamente sobre esta afetação, o humano se põe na tarefa filosófica fundamental, nomeando o Ser em essência, ou seja, se colocando no ato de criação poética e pronunciando a palavra correspondente à verdade. Assim como em Nietzsche, a verdade em Heidegger parte, em primeiro lugar, de uma atenção sobre a imanência e sua aparência, isto é, um ato experiencial sobre o ente em sua facticidade, um estar e ser no mundo. Em segundo lugar, assim como em Nietzsche, a verdade para Heidegger desvela-se a partir do instante, da situação e circunstância vivida e experienciada, que deve ser interpretada e expressa em forma de arte.

Para Heidegger (2009b), ao lançar luz sobre o Ser, mediante o pensamento em circunstância, (em meio à imanência), e assim nomeá-lo poeticamente, de imediato também ocorre o seu ocultamento, exigindo do ser humano um novo desvelar. Desta forma se estabelece o eterno jogo de luz e sombra, desvelamento e ocultamente que tanto marca o pensamento de Heidegger. Tal jogo evidencia a verdade em Heidegger (2009a) também enquanto um ato de criação circunstancial. Uma verdade, que ao contrário de Nietzsche se coloca enquanto essência do verdadeiro, mas que ao mesmo, tempo não se sustenta enquanto princípio metafísico incondicionado, ou verdade única e última. A verdade para Heidegger (2009a) apresenta uma efemeridade circunstancial como algo que está sempre por-vir, portanto, sendo, ou seja, ela se faz possível a cada situação, tanto em suas diferenças (particularidade), quanto em sua mesmidade e identidade.

Para Malpas (2008) e Pádua (2012), esse jogo eterno entre sombra e luz que marca o lugar heideggeriano enquanto o solo para o ato circunstancial de questionalidade e desvelamento do Ser, corresponde também à topologia contida no embate terra-mundo expressa na fase madura de Heidegger. A terra em Heidegger é a profundeza abismal do que está oculto no lugar, a angustia e escuridão correspondente ao que não desvelamos, não concebemos ainda, aquilo que já esta dado, o ser subsistente que é a própria natureza, a força autônoma e criadora do cosmo. Já o mundo é a dimensão iluminada, a terra desvelada, conhecida e habitada pelo modo de existir humano, sua questionalidade, pensamento e nomeação. $O$ mundo corresponde às possibilidades abertas após o ato de desencobrimento do Ser, portanto ele se desdobra a partir do lugar. No entanto, assim como no antagonismo referente ao ato de desvelamento, o mundo, enquanto lugar iluminado, logo 
se oculta em seu eterno por-vir, exigindo de nos humanos um esforço contínuo e interminável de decifração.

Em minha interpretação à topologia de Heidegger se dá no seguinte movimento: do lugar se concebe o mundo e do mundo partimos em busca de novos lugares a se desvelar. A esse jogo eterno corresponde o embate luz e sombra, terra-mundo da filosofia de Heidegger. Uma justa ou combate que pode ser entendida em similaridade ao pensamento trágico contido na filosofia de Nietzsche. Usufruindo da leitura de Machado (2006), concebemos que a cosmologia de Nietzsche é marcada por um antagonismo fundamental.

Como já explorado no terceiro tópico deste texto, o conflito (ou agonismo) que marca a dinâmica das múltiplas vontades de potência, corresponde, em Nietzsche, à tragédia entre as forças apolíneas e dionisíacas. Dionísio em Nietzsche corresponde ao sentido de terra discorrido, ou seja, a profundeza oculta, o caos cósmico sem ordem, (sem começo nem fim), o mau valor para a tradição, o terror e as trevas do imensurável e incompreendido, o corpo, o instinto, o desejo destrutivo e a vontade, as forças da natureza e o fundamento da existência, de onde tudo aflora e emerge. Apolo para Nietzsche é luz que resplandece do esforço humano de compreensão, a razão e a consciência do homem, o lançar ordem e finalidade sobre o mundo, o apaziguamento dos conflitos e das vontades, o belo, o bem e verdadeiro, a potência edificante que busca, inutilmente, domesticar a terra.

Apolo e Dionísio, ao mesmo tempo em que expressam uma oposição, também trazem consigo uma complementaridade necessária e indispensável. Para Nietzsche o jogo da vida é o agon (luta) trágico e eterno entre Apolo e Dionísio, homem e terra, luz e escuridão, abismo e topo, bem e mau.

\section{Desfecho em aberto}

Até aqui, o esforço dessa proposição se comprometeu em apontar e elucidar como o peculiar humanismo, a cosmologia e a geofilosofia contida no pensamento nietzschiano, assim como seus referentes sentidos de terra, trágico e verdade, estão presentes não só na topologia, como também na fenomenologia (e ontologia) hermenêutica de Heidegger. Como decorrência dessa investigação, ousamos dizer que esse encontro e enfrentamento entre os filósofos se faz presente também nos fundamentos da geografia humanista e, sobretudo, fenomenológica, tendo (até o momento) Eric Dardel como seu primeiro e principal anunciador.

Poderíamos ir além de Heidegger e em breves momentos fomos. Paralelo as incursões em Heidegger, Gaston Bachelard, que também dedicou parte de sua obra a leitura e análise sobre Nietzsche, havia surgido em nosso esforço como possível 
interlocutor. Bachelard (2001) aponta que Nietzsche era um "poeta e pensador do ar" que fez do duelo trágico entre materialidade e psiquismo (imaginação) meios para a superação do pensamento, enquanto ascensão da vontade de potência. Não estaria aí uma proposta de poética de conhecimento e decifração da terra inspiradora para a fenomenologia? Dardel foi capaz de trazê-la para sua geograficidade.

Recentemente pude apreciar possíveis intersecções entre Nietzsche e MerleauPonty (1999) a respeito do corpo enquanto realidade imediata. Na proposta de ambos os filósofos o corpo deve ser visto para além das cisões dicotômicas do pensamento moderno. Em suas leituras o corpo é existência imediata, um acontecimento de onde eclode não só a percepção sensível como o próprio pensar e a consciência. Além disso, o corpo é uma expressão criadora de sentido, um guia e fio condutor interpretativo para a criação de valores, avaliações e proposições filosóficas. Não estaria aí mais uma senda nietzschiana incorporada e aproveitada pelo caminhar da fenomenologia recente?

Se nosso trabalho revela algum ineditismo, este certamente não corresponde ao fato de termos aproximado Nietzsche da Geografia, tão pouco de sua vertente humanista, tendo como exemplo alguns dos trabalhos mencionados. Todavia, aproximar Nietzsche da Geografia fenomenológica, assim como da própria fenomenologia, trata-se de um dos temas mais escassos, arisco dizer: inexplorado.

Esperamos, modestamente, fazer algum ruído, por menor que seja, diante deste profundo silêncio e trazer Nietzsche para um profícuo diálogo com as possibilidades do fazer científico e geográfico. Como já salientado, no início deste escrito, esse é um caminho que, apesar de se estender por mais ou menos três anos, ainda não se encerrou e talvez nunca termine no devir de seus questionamentos. Espero que esse caminhar continue, não só pelo meu entusiasmo, mas pelo interesse e necessidade de outros geógrafos, pertencentes ou não as vertentes humanistas e fenomenológicas.

Ainda há muitas cordilheiras para desafiar...

\section{Referências}

Astor, D. (2013). Nietzsche (G. de A. Feix, Trad.). Porto Alegre: L\&PM.

Bachelard, G (1978). A poética do espaço. In: PESSANHA, J. A. M. (Org.) Os pensadores (J. J. M. Ramos, Trad.), São Paulo: Abril Cultural.

Bachelard, G. (2001). O ar e os sonhos: Ensaio sobre a imaginação do movimento (P. Neves, Trad.). São Paulo: WMF Martins Fontes.

Bachelard, G. (2003a). A Terra e os devaneios do repouso: Ensaio sobre as imagens da intimidade (P. Neves, Trad.). São Paulo: WMF Martins Fontes. 
Bachelard, G. (2003b). A Terra e os devaneios da vontade: Ensaio sobre a imaginação das forças (P. Neves, Trad.). São Paulo: WMF Martins Fontes.

Barrenechea, M. A. (2009). Nietzsche e o corpo. Rio de Janeiro: 7Letras.

Buttimer, Anne. (1990). Geography, Humanism, and Global Concern. Annals of the Association of American Geographers, 80 v.1, pp. 1-33,1990.

Davim. D. E. M. (2015). As forças em luta: segredos entre Nietzsche, Bachelard e Dardel sobre as vontades da terra. In: Encontro Nacional de Pós-graduação em Geografia, Presidente Prudente, 2015. Anais... Presidente Prudente: UFGD, 2015. http://www.enanpege.ggf.br/2015/anais/arquivos/17/499.pdf.

Davim. D. E. M. (2016). Gaia-graphein: Nietzsche e a geografia. In: IV Encontro Nacional de História do Pensamento Geográfico \& II Encontro Nacional de Geografia Histórica, Belo Horizonte, 2016. Anais... Belo Horizonte: UFMG, 2016.

Dal Gallo, P. M. \& Marandola Jr. E. (2015). O pensamento heideggeriano na obra de Éric Dardel: a construção de uma ontologia da geografia como ciência existencial. Revista da Associação Nacional de Pós-graduação e Pesquisa em Geografia (Anpege), v.11, n.16, p.173-200, jul-dez. 2015.

Dardel, E. (2011). O Homem e a Terra: natureza da realidade geográfica (W. Holzer, Trad.). São Paulo: Editora Perspectiva.

D'iorio, P. (2014) Nietzsche na Itália: a viagem que mudou os rumos da filosofia (J. A. d'Avila Melo, Trad.). Rio de Janeiro: Zahar.

Feitosa, C. (2011). Filosofia e Geografia em Nietzsche. In: Barrenechea, M. A. (Org.). Nietzsche e as ciências. Rio de Janeiro: 7letras, p. $139-149$.

Gomes, P. C. C. (2010). Geografia e Modernidade. Rio de Janeiro: Bertrand Brasil, 2011.

Gros, F. (2010). Caminhar, uma filosofia (L. L. da Silva, Trad.). São Paulo: É Realizações.

Günzel, S. (2003). Nietzsche's Geophilosophy. Journal of Nietzsche Studies, New York, v. 25, n.1, p. 78 - 91, 2003.

Haesbaert, R. \& Bruce, G. (2002). A desterritorialização na obra de Deleuze e Guattari. Geographia, Niterói, v. 4, n. 7, p. 7-22, 2002.

Heidegger, M. (2009a). Introdução à Filosofia (M. A. Casanova, Trad.). São Paulo: WMF, Martins Fontes.

Heidegger, M. (2009b). Sobre o Humanismo (E. C. Leão, Trad.). Rio de Janeiro: Tempo Brasileiro.

Heidegger, M. (2010). Nietzsche (1) (M. A. Casanova, Trad.). Rio de Janeiro: Forense Universitária.

Heidegger, M. (2012b). Ser e tempo (M. S. C. Schuback ,Trad.). Petrópolis: Vozes.

Kingsbury, P. (2010a) Editorial Introduction: Friedrich Nietzsche and Geography. ACME: An International E-Journal for Critical Geographies, Okanagan, v. 9 (1), p. 1 - 9, 2010a. 
Lefebvre, H. (2006). A produção do espaço (D. B. Pereira \& S. Martins, Trads.). Original: La production de l'espace. 4e éd. Paris: Éditions Anthropos, 2000.

http://www.mom.arq.ufmg.br/mom/arq_interface/1a_aula/A_producao_do_espaco.pdf

Machado, R. (2006). O Nascimento da Tragédia: de Schiller a Nietzsche. Rio de Janeiro: Jorge Zahar.

Machado, R. (2014). A Geography of Philosophical Thought. Deleuze International, v. 03, p. 1-15, 2014.

Malpas, J. (2008). Heidegger's topology: being, place, world. Cambridge: MIT press, 2008.

Marton, S. (2010). Nietzsche: das forças cósmicas aos valores humanos. Belo Horizonte: UFMG.

Merleau-Ponty, M. (1999). Fenomenologia da Percepção (C. A. R. de Moura, Trad.). São Paulo: WMF Martins Fontes.

Müller-Lauter, W. (2009). Nietzsche: sua filosofia dos antagonismos e os antagonismos de sua filosofia (C. Araldi, Trad.). São Paulo: Unifesp.

Nietzsche, F. (2009). Genealogia da moral: uma polêmica (P. C. de Souza, Trad.). São Paulo. Companhia das Letras.

Nietzsche, F. (2011a). A Gaia Ciência. (P. C. de Souza, Trad.). São Paulo: Companhia das Letras.

Nietzsche, F. (2011b). Assim falou Zaratustra: um livro para todos e para ninguém (P. C. de Souza, Trad.). São Paulo: Companhia das letras.

Nietzsche, F. (2012). Humano Demasiado Humano: um livro para espíritos livres (P. C. de Souza, Trad.). São Paulo: Companhia das letras.

Nietzsche, F. (2014). Além do bem e do mal: prelúdio de uma filosofia do futuro (P. C. de Souza, Trad.). São Paulo: Companhia das Letras.

Peet, R. \& Hartwick, E. (2009). Theories of Development: Contentions, Arguments, Alternatives. New York: The Guilford Press.

Pádua, L. T. S. (2012). Como ponta de lança: o pensamento do lugar em Heidegger. In: Marandola Jr. E., Holzer, W. \& OLIVEIRA, L.(Orgs). Qual é o espaço do lugar? São Paulo: Perspectiva.

Stegmaier, W. (2013). As linhas fundamentais do pensamento de Nietzsche: coletânea de artigos (O. Giacoia Jr. Trad.). Petrópolis: Editora Vozes.

Wainwright, J. (2010). Nietzsche Contra the Real World. ACME: An International E-Journal for Critical Geographies, Okanagan, v. 9 n.1, p. 21-33, 2010.

\section{Nota sobre o autor}

David Emanuel Madeira Davim. Doutorando em Geografia pela Universidade Estadual de Campinas - IG - Instituto de Geociências. E-mail: davidavim@hotmail.com. 